Author affiliations appear at the end of this article.

Published online ahead of print at www.jco.org on September 8, 2014

American Society of Clinical Oncology Clinical Practice Guideline Committee approval: April 26, 2013; Systematic Review by Cancer Care Ontario Program in EvidenceBased Care's Leadership approval: August 9, 2013.

Editor's note: This joint American Society of Clinical Oncology and Cancer Care Ontario Clinical Practice Guideline provides recommendations, with comprehensive discussions of methodology and relevant literature for each statement. Additional information, including Data Supplements and clinical tools and resources, is available at http://www.asco.org/guidelines/mCRPC and https://mww.cancercare.on.ca/toolbox qualityguidelines/diseasesite/genito-ebs/.

Opinions expressed in this article should not be interpreted as the official positions of any US or Canadian governmental agency, including the National Cancer Institute, National Institutes of Health, US Food and Drug Administration, or US Department of Health and Human Services.

Authors' disclosures of potential conflicts of interest and author contributions are found at the end of this article.

Corresponding author: American Society of Clinical Oncology, 2318 Mill Rd, Suite 800, Alexandria, VA 22314; e-mail:

guidelines@asco.org

C 2014 by American Society of Clinical Oncology

0732-183X/14/3230w-3436w/\$20.00

DOI: 10.1200/JCO.2013.54.8404

\title{
Systemic Therapy in Men With Metastatic Castration-Resistant Prostate Cancer: American Society of Clinical Oncology and Cancer Care Ontario Clinical Practice Guideline
}

Ethan Basch, D. Andrew Loblaw, Thomas K. Oliver, Michael Carducci, Ronald C. Chen, James N. Frame, Kristina Garrels, Sebastien Hotte, Michael W. Kattan, Derek Raghavan, Fred Saad, Mary-Ellen Taplin, Cindy Walker-Dilks, James Williams, Eric Winquist, Charles L. Bennett, Ted Wootton, R. Bryan Rumble, Stacie B. Dusetzina, and Katherine S. Virgo

See accompanying article on page 3391; listen to the podcast by Drs Suzman and Antonarakis at wWw.jco.org/podcasts

$\begin{array}{llllllll}\text { A } & \text { B } & \text { S } & \text { T } & \text { R } & \text { A } & \text { C } & \text { T }\end{array}$

\section{Purpose}

To provide treatment recommendations for men with metastatic castration-resistant prostate cancer (CRPC)

\section{Methods}

The American Society of Clinical Oncology and Cancer Care Ontario convened an expert panel to develop evidence-based recommendations informed by a systematic review of the literature.

\section{Results}

When added to androgen deprivation, therapies demonstrating improved survival, improved quality of life (QOL), and favorable benefit-harm balance include abiraterone acetate/prednisone, enzalutamide, and radium-223 ( ${ }^{223} \mathrm{Ra}$; for men with predominantly bone metastases). Improved survival and $\mathrm{QOL}$ with moderate toxicity risk are associated with docetaxel/prednisone. For asymptomatic/minimally symptomatic men, improved survival with unclear QOL impact and low toxicity are associated with sipuleucel-T. For men who previously received docetaxel, improved survival, unclear $\mathrm{QOL}$ impact, and moderate to high toxicity risk are associated with cabazitaxel/prednisone. Modest QOL benefit (without survival benefit) and high toxicity risk are associated with mitoxantrone/prednisone after docetaxel. No benefit and excess toxicity are observed with bevacizumab, estramustine, and sunitinib.

\section{Recommendations}

Continue androgen deprivation (pharmaceutical or surgical) indefinitely. Abiraterone acetate/ prednisone, enzalutamide, or ${ }^{223} \mathrm{Ra}$ should be offered; docetaxel/prednisone should also be offered, accompanied by discussion of toxicity risk. Sipuleucel-T may be offered to asymptomatic/minimally symptomatic men. For men who have experienced progression with docetaxel, cabazitaxel may be offered, accompanied by discussion of toxicity risk. Mitoxantrone may be offered, accompanied by discussion of limited clinical benefit and toxicity risk. Ketoconazole or antiandrogens (eg, bicalutamide, flutamide, nilutamide) may be offered, accompanied by discussion of limited known clinical benefit. Bevacizumab, estramustine, and sunitinib should not be offered. There is insufficient evidence to evaluate optimal sequences or combinations of therapies. Palliative care should be offered to all patients.

\section{J Clin Oncol 32:3436-3448. (C) 2014 by American Society of Clinical Oncology}

\section{INTRODUCTION}

Prostate cancer is the second leading cause of cancer deaths among North American men, with an estimated 29,720 deaths in 2013 in the United States ${ }^{1}$ and 3,900 deaths in Canada. ${ }^{2}$ For men with androgen-sensitive metastatic disease, continuous androgen-deprivation therapy is the current standard of care. ${ }^{3}$ Ultimately, many of these men will develop castration-resistant prostate cancer (CRPC), warranting additional lines of therapy added to androgen-deprivation therapy. ${ }^{4}$ This guideline pertains to men with CRPC and radiographically or pathologically demonstrated metastases. 


\section{ASCO GUIDELINE UPDATE}

Recommendations From American Society of Clinical Oncology and Cancer Care Ontario for Systemic Therapy in Men With Metastatic Castration-Resistant Prostate Cancer, Based on Standardized Ratings of Clinical Benefit, Harm, Evidence Strength, and Recommendation Strength*

\section{Guideline Question}

- Which systemic therapies improve outcomes in men with metastatic castration-resistant prostate cancer (CRPC)?

\section{Target Audience and Population}

- The target audience for this guideline comprises medical, radiation, and urologic oncologists who treat men with metastatic CRPC. These recommendations are also intended to inform patients, caregivers, health care professionals, health care administrators, and policymakers.

\section{Methods}

- Expert panel recommendations based on a systematic review of the medical literature updated to June 2014.

\section{Recommendations}

\section{Androgen-Deprivation Therapy:}

- Continuous androgen deprivation (pharmaceutical or surgical) should be continued indefinitely regardless of additional therapies. (Benefit: moderate; harm: moderate; evidence strength: weak; recommendation strength: moderate)

\section{Therapies in Addition to Androgen-Deprivation Therapy:}

Therapies with demonstrated survival and quality-of-life benefits:

- Abiraterone acetate and prednisone should be offered.

(Benefit: moderate; harm: low; evidence strength: strong; recommendation strength: strong)

- Enzalutamide should be offered.

(Benefit: moderate; harm: low; evidence strength: strong; eecommendation strength: strong)

- Radium-223 should be offered to men with bone metastases.

(Benefit: moderate; harm: low; evidence quality: strong; recommendation strength: strong)

- Docetaxel and prednisone should be offered. $\dagger$

(Benefit: moderate; harm: moderate; evidence strength: strong; recommendation strength: moderate)

\section{Therapies with demonstrated survival benefit and unclear quality-of-life benefit:}

- Sipuleucel-T may be offered to men who are asymptomatic or minimally symptomatic. (Benefit: moderate; harm: low; evidence strength: moderate; recommendation strength: weak)

- Cabazitaxel and prednisone may be offered to men who experience progression with docetaxel (Benefit: moderate; harm: moderate to high; evidence strength: strong; recommendation strength: moderate)

\section{Therapies with quality-of-life benefit without demonstrated survival benefit:}

- Mitoxantrone plus prednisone may be offered.

(Benefit: low; harm: high; evidence strength: weak; recommendation strength: weak)

\section{Therapies with biologic activity and unknown survival or quality-of-life benefit:}

- Antiandrogens (eg, bicalutamide, flutamide, nilutamide) may be offered.

(Benefit: low; harm: low; evidence strength: weak; recommendation strength: weak)

- Ketoconazole may be offered.

(Benefit: low; harm: moderate; evidence strength: weak; recommendation strength: weak)

- Low-dose corticosteroid monotherapy may be offered.

(Benefit: low; harm: low; evidence strength: weak; recommendation strength: weak)

(continued on following page) 


\section{Therapies without demonstrated survival or quality-of-life benefit:‡}

- Bevacizumab should not be offered.

(Benefit: none; harm: high; evidence strength: moderate; recommendation strength: strong)

- Estramustine should not be offered.

(Benefit: none; harm: high; evidence strength: moderate; recommendation strength: strong)

- Sunitinib should not be offered.

(Benefit: none; harm: high; evidence strength: moderate; recommendation strength: strong)

\section{Palliative Care Services}

- Palliative care should be offered to all patients, particularly to those exhibiting symptoms or quality-of-life (QOL) decrements, regardless of treatment type.

(Benefit: moderate; harm: none; evidence strength: moderate; recommendation strength: strong)

\section{Qualifying Statements}

- Clinicians are advised to review the published regimens discussed in this guideline for their use in appropriate patient populations and for applicable dose selections/modifications, available from the product labels.

- There is insufficient published evidence to recommend specific sequencing of these therapies or combinations of these therapies, except as otherwise noted.

- The distinction made in some clinical trials between pre- and postdocetaxel treatment contexts should not play a role in selecting therapies for individual patients, unless otherwise noted.

- Patients may place a higher importance on QOL rather than length of life. It is essential to understand individual patient values and preferences for appropriate treatment decision making. Many patients with incurable metastatic disease misperceive the goals of care to be curative. Clear communication about goals as well as potential benefits and harms of care should be prioritized.

- Cost and availability considerations may reasonably influence treatment decisions. There is wide variation in the financial burden individual patients face for various therapies, and this potential barrier or hardship should be openly discussed with patients.

- Most phase III clinical trials have included patients with good baseline performance status. The choice of treatment for patients with diminished performance status is not clearly informed by existing evidence in most cases.

\section{Additional Resources}

- More information, including a Data Supplement with additional evidence tables, a Methodology Supplement with information about evidence quality and strength of recommendations, slide sets, and clinical tools and resources, is available at www.asco.org/ guidelines/mCRPC. Patient information is available at www.cancer.net.

*Criteria for ratings of clinical benefit, harm, strength of evidence, and strength of recommendations are shown in Methodology Supplement.

tRecent data suggest a substantial survival benefit when adding a limited course of docetaxel to androgen-deprivation therapy in the setting of newly diagnosed metastatic androgen-sensitive prostate cancer, primarily in men with a high burden of metastatic disease at presentation (visceral disease and/or > four bone metastatic lesions). The additive benefits or toxicities associated with subsequently retreating such patients with docetaxel in the castration-resistant setting are not known. ${ }^{45}$

‡Drug products are listed that have obtained regulatory approval and market availability for other indications. Products with negative phase III clinical trial evidence are not listed if they are not approved or available.

This guideline builds on prior recommendations from the American Society of Clinical Oncology (ASCO) and Cancer Care Ontario (CCO). In 2006, the CCO Genitourinary Cancer Disease Site Group developed a guideline on nonhormonal therapies for men with metastatic CRPC based on a systematic review of 28 randomized controlled trials (RCTs) published between 1979 and $2004 .^{5}$ In 2007, ASCO endorsed the CCO guideline, ${ }^{6}$ which recommended docetaxel with prednisone as the mainstay of treatment for patients with symptomatic metastatic CRPC. ${ }^{7}$
In an update of the literature through June $2012,{ }^{8} \mathrm{CCO}$ expanded the scope of the prior systematic review to include targeted therapies and immunotherapy. That review included an additional 25 RCTs. ${ }^{5,8}$ On the basis of this evidence, ASCO and CCO convened an expert panel to provide the current recommendations for systemic therapy in metastatic CRPC. A description of standardized criteria used by ASCO and CCO to make these recommendations is shown in the Methodology Supplement. These criteria include evaluations of the strength of published evidence, clinical benefit, and risk of harm. 
Topics not specifically covered in this guideline include management of patients with androgen-sensitive prostate cancer, management of prostate cancer recurrence based solely on detection of serum prostate-specific antigen (PSA) without radiographic or pathologic evidence of metastases (ie, biochemical progression), and bone health in CRPC.

\section{GUIDELINE QUESTION}

Which systemic therapies improve outcomes in men with metastatic CRPC?

\section{METHODS}

\section{Panel Composition}

The ASCO Clinical Practice Guidelines Committee and CCO Program in Evidence-Based Care convened an expert panel with multidisciplinary representation in medical oncology, urologic oncology, radiation oncology, community oncology, patient advocacy, health services, implementation research, and guideline methodology. Members of the expert panel are listed in Appendix Table A1 (online only).

\section{Guideline Development Process}

The expert panel met on several occasions and corresponded frequently through e-mail; work on the guideline was completed primarily through the writing group, along with ASCO staff. The purpose of the panel meetings was for members to contribute content, provide critical review, and finalize the guideline recommendations, including an assessment of benefits and harms associated with treatments based on consideration of the evidence. All members of the expert panel participated in preparation of the draft guideline document, which was then disseminated for external review and submitted to Journal of Clinical Oncology (JCO) for peer review. All ASCO guidelines are reviewed and approved by the ASCO Clinical Practice Guideline Committee on behalf of the ASCO Board before publication. All CCO guidelines are reviewed and approved by the CCO Report Approval Panel and a topicspecific disease site group (in this instance, the CCO Genitourinary Disease Site Group).

\section{Guideline Disclaimer}

ASCO Clinical Practice Guidelines and other guidance published herein are provided by ASCO to assist providers in clinical decision making. The information herein should not be relied on as being complete or accurate, nor should it be considered as inclusive of all proper treatments or methods of care or as a statement of the standard of care. With the rapid development of scientific knowledge, new evidence may emerge between the time information is developed and when it is published or read. The information is not continually updated and may not reflect the most recent evidence. The information addresses only the topics specifically identified herein and is not applicable to other interventions, diseases, or stages of disease. This information does not mandate any particular course of medical care. Furthermore, the information is not intended to substitute for the independent professional judgment of the treating provider, because the information does not account for individual variation among patients. Recommendations reflect high, moderate, or low confidence that the recommendation reflects the net effect of a given course of action. Use of words like must, must not, should, and should not indicates that a course of action is recommended or not recommended for either most or many patients, but there is latitude for the treating physician to select other courses of action in individual cases. In all cases, the selected course of action should be considered by the treating provider in the context of treating the individual patient. Use of the information is voluntary. ASCO provides this information on an as-is basis and makes no warranty, express or implied, regarding the information. ASCO specifically disclaims any warranties of merchantability or fitness for a particular use or purpose. ASCO assumes no responsibility for any injury or damage to persons or property arising out of or related to any use of this information or for any errors or omissions.

\section{Guideline and Conflicts of Interest}

The expert panel was assembled in accordance with the ASCO Conflict of Interest Management Procedures for Clinical Practice Guidelines (summarized at http://www.asco.org/rwc). Members of the panel completed the ASCO disclosure form, which requires disclosure of financial and other interests that are relevant to the subject matter of the guideline, including relationships with commercial entities that are reasonably likely to experience direct regulatory or commercial impact as a result of promulgation of the guideline. Categories for disclosure include employment relationships, consulting arrangements, stock ownership, honoraria, research funding, and expert testimony. In accordance with these procedures, the majority of the members of the panel did not disclose any such relationships. The Methodology Supplement provides full guideline disclaimers from CCO.

\section{Literature Review}

ASCO and CCO guidelines are based on systematic reviews of the literature. A protocol for each systematic review defines parameters for a targeted literature search. Additional parameters include relevant study designs, literature sources, types of reports, and prespecified inclusion and exclusion criteria for identified literature. This guideline protocol was reviewed and approved by the ASCO Clinical Practice Guidelines Committee Methodology Subcommittee and the CCO Program in Evidence-Based Care leadership.

\section{Literature Search Strategy}

For this clinical practice guideline, the literature search to June 2012 and results of the systematic review conducted by $\mathrm{CCO}^{8}$ were considered to be of high quality and currency to be endorsed for use by the guideline expert panel. An updated search of the Medline database was conducted to June 2014 to search for any additional RCTs that could inform recommendations. The literature search will be replicated for periodic updates of the guideline. Additions to this guideline were triggered by publications and meeting presentations of phase III clinical trials through June 2014.

\section{Study Selection Criteria}

Articles were selected for inclusion in the CCO systematic review if they:

- Were RCTs or evidence synthesis products based on RCTs

- Included men with metastatic CRPC

- Compared systemic therapy, alone or in combination with other agents, versus placebo or other drug regimens

- Were published English-language reports

Articles were excluded from the systematic review if they involved only androgen-deprivation therapy, bone targeted agents, or radionuclides. Trials were required to have $\geq 50$ patients per study arm, and in mixed study populations, $\geq 90 \%$ of men were required to have metastases.

\section{RESULTS}

On the basis of a 2012 CCO systematic review ${ }^{8}$ and an updated search of the Medline database to June 2014, a total of 26 RCTs $^{9-37}$ informed this clinical practice guideline (Table 1). Publication of the phase III ALSYMPCA (Alpharadin in Symptomatic Prostate Cancer) trial, ${ }^{31}$ evaluating radium-223 $\left({ }^{223} \mathrm{Ra}\right)$ and US Food and Drug Administration approval of this product in May 2013, and publication of the phase III PREVAIL trial, ${ }^{38}$ evaluating enzalutamide in the prechemotherapy setting, prompted inclusion of these data for this guideline. Although only the most recent reports from multiple publications are referenced throughout, supporting evidence is also cited where appropriate. A search for clinical practice guidelines developed in 2013 yielded two clinical practice guidelines, one by the National Comprehensive Cancer Network (NCCN) ${ }^{39}$ and the other by the American Urological Association (AUA). ${ }^{40}$ 


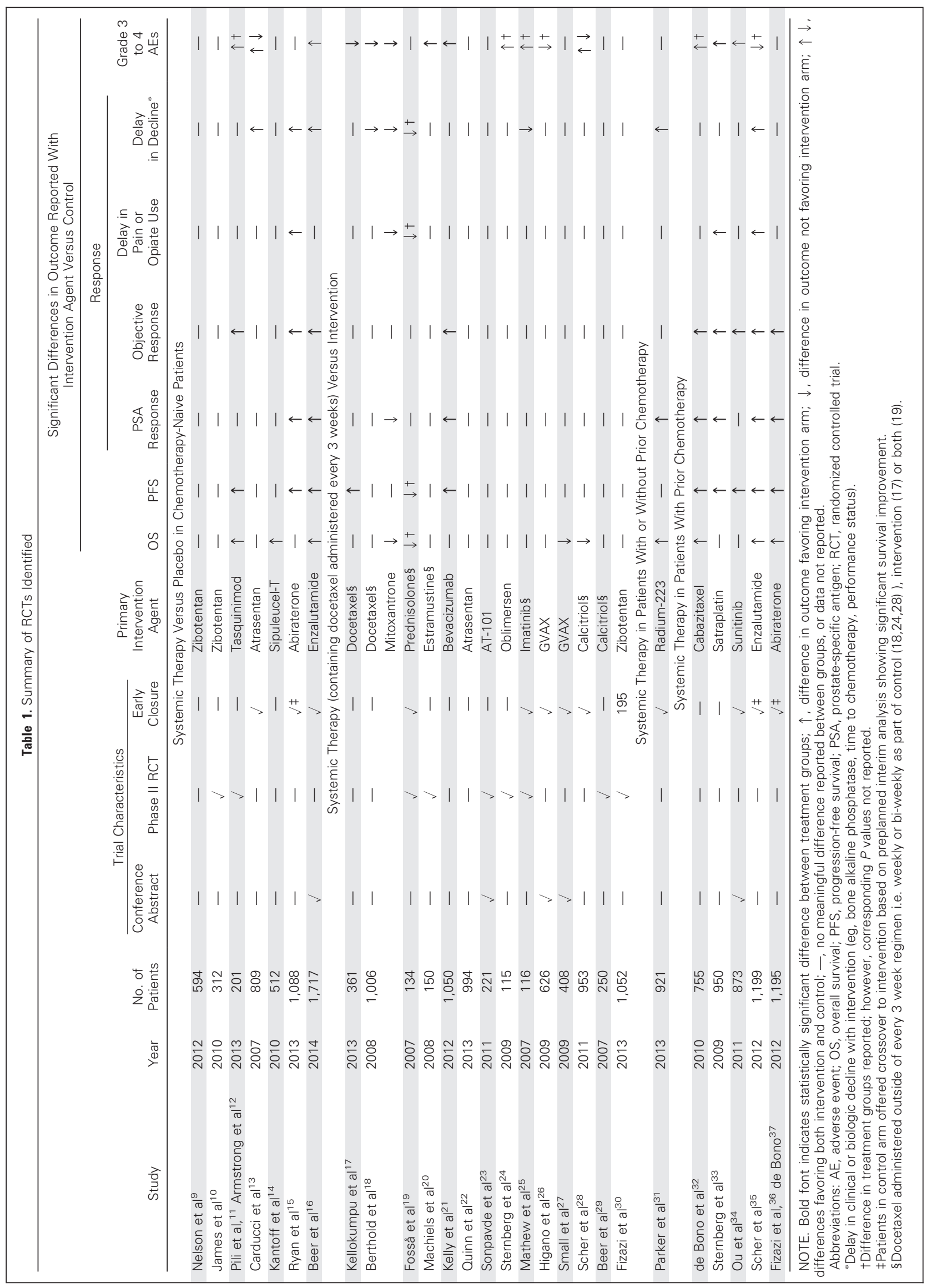


Table 2. Summary of CCO Quality Assessment of Included RCTs

\begin{tabular}{lrrr}
\hline \multicolumn{1}{c}{ Criterion } & Yes & No & Not Reported \\
\hline Was allocation sequence reported? & 16 & 0 & 9 \\
Was concealed allocation reported? & 6 & 0 & 19 \\
Was sample size/power calculation reported? & 16 & 4 & 5 \\
Was blinding reported? & 16 & 6 & 3 \\
Was intention to treat reported? & 13 & 9 & 3 \\
Was patient withdrawal described? & 14 & 0 & 11 \\
Was industry funding reported? & 15 & 1 & 9 \\
Was loss to follow-up reported? & 13 & 0 & 12 \\
Were baseline characteristics balanced? & 17 & 3 & 5 \\
Was trial terminated early? & 7 & 18 & 0 \\
\hline
\end{tabular}

NOTE. In assessment of quality, "yes" indicates that quality metric was met and/or was specifically reported, whereas "no" indicates that quality metric was not met. "Not reported" indicates that quality metric may or may not have been met; however, because it was not reported, it was not possible to assess.

Abbreviations: CCO, Cancer Care Ontario; $\mathrm{RCT}$, randomized controlled trial.

\section{Study Quality Assessment and Limitations of Literature}

In the CCO review, ${ }^{8}$ study quality was formally assessed and summarized by one reviewer for the RCTs identified. In that review, design aspects related to individual study quality were generally assessed as moderate to high quality, with factors such as blinding, allocation concealment, placebo control, intention to treat, and funding sources, generally indicating a relatively low risk of bias for most of the identified trials (Table 2). Since the time of that quality appraisal, two of the trials have published their findings, with additional details reported around quality elements. Hence, the quality appraisal from the CCO review is slightly more conservative in its estimation of potential biases associated with the body of evidence.

Several factors related to increased potential for bias for the overall body of evidence to inform recommendations were also reported. Seven of the trials were phase II studies, seven trials were terminated early, three trials offered crossover after preplanned interim analyses, and four trials were reported as conference proceedings (Table 1). Primary outcomes varied across the trials, and in the majority of cases, studies were not directly comparable, because different treatments and regimens were used at different time points in the patient treatment trajectory.

One included phase III double-blind $\mathrm{RCT}^{31}$ was published subsequent to the CCO quality appraisal. ${ }^{8}$ In that trial, 921 patients were randomly assigned at a ratio of two to one to ${ }^{223} \mathrm{Ra}$ or placebo. That trial was terminated for efficacy as part of a preplanned interim analysis. Using the same quality metrics reported in the $\mathrm{CCO}$ review, that trial was not considered to be at high risk of potential bias.

\section{Clinical Practice Guidelines}

Two clinical practice guidelines were identified, one by the $\mathrm{NCCN}^{39}$ and one by the AUA. ${ }^{40}$ A summary of these recommendations is presented in the Data Supplement. Although the recommendations from the NCCN, AUA, and ASCO/CCO guidelines are similar, the ways in which therapies are categorized differ. The NCCN guideline ${ }^{39}$ separates patients by nonmetastatic versus metastatic and nonsymptomatic versus symptomatic status and further separates symptomatic patients by first- or second-line treatment. The AUA guideline $^{40}$ separates patient populations by nonmetastatic versus metastatic status and further divides the metastatic patients by prior docetaxel versus no prior docetaxel, asymptomatic versus symptomatic status, and good versus poor performance status. In contrast, this guideline categorizes and evaluates therapies based on type of clinical benefit (survival and/or quality of life [QOL]), strength of evidence, and benefit-risk balance. Pertinence of particular therapies to presence of symptoms, bone metastases, or prior treatments is noted at the individual therapy level.

\section{Trial Results}

As listed in Table 1, six trials investigated systemic therapy agents delivered before chemotherapy-containing regimens. ${ }^{9,10,12-15}$ Thirteen RCTs compared docetaxel-containing systemic therapy as control versus other cytotoxic chemotherapy, targeted therapy, or immunotherapy, with or without docetaxel, as the intervention. ${ }^{11-13,18,19,22-25,29,32-35}$ One RCT compared ${ }^{223} \mathrm{Ra}$ with placebo among patients with or without prior chemotherapy exposure, ${ }^{31}$ and five trials investigated systemic therapy agents administered to patients who had previously received docetaxelcontaining chemotherapy. ${ }^{15,36,39,41-43}$ Details of the evidence are described here, organized alphabetically by individual drug product name.

Abiraterone acetate. In a phase III trial of abiraterone acetate plus prednisone administered in men with metastatic CRPC who had not received chemotherapy and were asymptomatic or beginning to exhibit symptoms, a statistically significant progression-free survival (PFS) difference was detected when compared with placebo plus prednisone (hazard ratio [HR], $0.43 ; 95 \%$ CI, 0.35 to $0.52 ; P<.001$ ).$^{15}$ Secondary outcomes, including time to opiate use, time to pain progression, chemotherapy initiation, functional status deterioration, and PSA progression, demonstrated significant benefit in favor of abiraterone acetate (all $P<.01$ ). Median overall survival $(\mathrm{OS})$ in the control group was 27.2 months, whereas median survival in the intervention group was not reached by the time of analysis (HR, $0.75 ; 95 \%$ CI, 0.61 to $0.93 ; P=.0097)$. The prespecified $\alpha$ level for OS was $P=$ .0008 ; hence, there was a trend, but statistical significance was technically not reached for that outcome. QOL was measured through patient report of pain using the Brief Pain Inventory-Short Form, and functional status was assessed using the Functional Assessment of Cancer Therapy-Prostate. Delay in pain was longer with abiraterone acetate, at 26.7 versus 18.4 months (HR, $0.82 ; 95 \% \mathrm{CI}, 0.67$ to 1.00 ; $P=.049$ ), as was the delay in functional decline, at 12.7 versus 8.3 months (HR, $0.78 ; 95 \% \mathrm{CI}$, 0.66 to $0.92 ; P=.003$ ). The toxicity profile associated with abiraterone acetate included a low rate of grade 3 to 4 adverse events, with no statistically significant differences between treatment groups reported.

In another phase III trial of abiraterone acetate plus prednisone in men who previously received docetaxel, ${ }^{36,37}$ significant differences in median OS ( $15.8 v 11.2$ months; HR, 0.74 ; $95 \%$ CI, 0.64 to 0.86 ; $P<$ $.001)$, median time to PSA progression ( $8.5 v 6.6$ months; HR, 0.63; $95 \%$ CI, 0.58 to $0.78 ; P<.001$ ), median radiographic PFS (5.6 $v 3.6$ months; HR, $0.66 ; 95 \% \mathrm{CI}$, 0.58 to $0.76 ; P<.001$ ), and PSA response $(29.5 \% v 5.5 \% ; P<.001)$ were detected in favor of abiraterone acetate when compared with prednisone plus placebo. Median time to functional decline was longer with abiraterone acetate, at 5 versus 3 months $(P<.001),{ }^{43}$ as were significant improvements in patient-reported fatigue, compared with prednisone alone. ${ }^{44}$ 
Cabazitaxel. For patients who experienced progression during or shortly after docetaxel treatment, a phase III trial comparing cabazitaxel plus prednisone versus mitoxantrone plus prednisone reported a significant OS benefit of 15.1 versus 12.7 months $(P<.001)$ and median PFS of 2.8 versus 1.4 months with cabazitaxel (HR, $0.74 ; 95 \%$ CI, 0.64 to $0.86 ; P<.001) .{ }^{32,41}$ QOL benefit was not clearly demonstrated (small nonsignificant improvement in pain compared with mitoxantrone was seen, although rates of pain palliation in both arms were low; overall or prostate-specific QOL was not assessed). ${ }^{38}$ Grade 3 to 4 adverse events, most commonly neutropenia ( $82 \% v 58 \%$; P not reported), febrile neutropenia ( $8 \% \vee 1 \%$; $P$ not reported), and diarrhea ( $6 \% v 1 \% ; P$ not reported), were greater in the cabazitaxel arm.

Docetaxel-containing regimens. A phase III trial of docetaxel plus prednisone administered every 3 weeks reported a significant OS advantage when compared with mitoxantrone plus prednisone (19.2 v 16.3 months; HR, $0.79 ; 95 \% \mathrm{CI}, 0.67$ to $0.93 ; P=.004)$ and no significant difference in survival compared with a second intervention arm of docetaxel once per week. ${ }^{18}$ There were significantly more grade 3 to 4 adverse events with docetaxel administered every 3 weeks when compared with mitoxantrone as well as with once-per-week docetaxel. In the once-per-week docetaxel arm, clinical benefit was generally greater than that seen with mitoxantrone but lower than that with docetaxel every 3 weeks, although these differences were not statistically significant. Using the Functional Assessment of Cancer Therapy-Prostate, functional status was significantly better with docetaxel administered every 3 weeks $(22 \%)$ or once per week $(23 \%)$ when compared with mitoxantrone $(13 \% ; P=.009$ and .005 , respectively). One docetaxel timing trial reported a longer time to treatment failure (5.6 $v 4.9$ months; $P=.016$ ) and fewer grade 3 to 4 toxicities overall with docetaxel administered every 2 versus every 3 weeks. ${ }^{17}$

Regarding the use of estramustine with docetaxel, in the original CCO guideline, one phase III trial reported that the combination of docetaxel and estramustine produced superior OS results when compared with mitoxantrone plus prednisone, but that regimen was not recommended on the basis of increased adverse events. ${ }^{5}$ In a subsequent phase II trial, the combination of docetaxel plus estramustine was not superior to docetaxel alone, and adverse events were greater in the estramustine arm. ${ }^{20}$

In five trials of docetaxel-containing chemotherapy with or without targeted therapy for patients with symptomatic metastatic CRPC, one trial reported that the addition of bevacizumab to docetaxel plus prednisone resulted in improved PFS (9.9 7.5 months; $P<.001)$, PSA response, and objective response but not OS when compared with docetaxel and prednisone alone. There were significantly more grade 3 to 4 adverse effects $(75 \% \vee 56 \% ; P<.001)$, including treatment-related death $(4.0 \% \vee 1.2 \% ; P<.005)$, when compared with the docetaxel control. ${ }^{21}$ No significant differences in clinically meaningful outcomes were detected in the remaining four RCTs. ${ }^{22-25}$

Recent data suggest a substantial survival benefit when adding a limited course of docetaxel to androgen-deprivation therapy in the setting of newly diagnosed metastatic androgen-sensitive prostate cancer. The additive benefits or toxicities associated with subsequently re-treating such patients with docetaxel in the castration-resistant setting are not known. ${ }^{45}$

Enzalutamide. In a phase III trial of 1,199 men with prior chemotherapy exposure who were randomly assigned to receive enzalutamide versus placebo, a statistically significant improvement in OS of 18.4 versus 13.6 months was detected with enzalutamide (HR, 0.63;
95\% CI, 0.53 to $0.75 ; P<.001) .{ }^{28,35}$ Radiographic PFS was 8.3 versus 2.9 months (HR, $0.40 ; P<.001$ ), PSA response was $54 \%$ versus $2 \%$ $(P<.001)$, time to PSA progression was 8.3 versus 3.0 months $(\mathrm{HR}$, $0.25 ; P<.001)$, and time to first skeletal-related event was 16.7 versus 13.3 months (HR, $0.69 ; P<.001$ ), all in favor of enzalutimide. Overall QOL benefit was observed in 43\% versus 18\% $(P<.001)$ of patients receiving enzalutamide compared with placebo, whereas fatigue, diarrhea, and hot flushes were more common with enzalutamide. Five patients $(0.6 \%)$ experienced seizures in the enzalutamide group. ${ }^{35}$

In one phase III trial, 1,717 men without prior chemotherapy exposure were randomly assigned to receive enzalutamide versus placebo. ${ }^{38}$ At data cutoff, $72 \%$ of men were alive in the enzalutamide arm compared with $63 \%$ in the placebo arm (risk reduction, $29 \%$; HR, 0.71; $P<.001)$. Significant improvements in PFS, PSA, skeletalrelated events, and QOL were also associated with enzalutamide over placebo. No new safety signals were detected (one seizure in each arm).

Mitoxantrone. A prior CCO systematic review reported on three small trials of mitoxantrone plus prednisone or hydrocortisone, which showed modest clinical benefit (including improved pain response, QOL, and/or time to disease progression) but no improvement in OS, and increased risk of harm, compared with treatment with prednisone or hydrocortisone alone. ${ }^{5}$ In a trial comparing mitoxantrone plus prednisone with prednisone alone during the era before availability of most contemporary prostate cancer therapies, there was a $29 \%$ pain response rate for mitoxantrone versus $12 \%$ for prednisone alone, ${ }^{46}$ although in a more contemporary phase III trial comparing cabazitaxel with mitoxantrone in men who had previously received docetaxel, mitoxantrone plus prednisone was associated with a $7.7 \%$ pain response rate. ${ }^{18}$

${ }^{223} \mathrm{Ra}$. The ALSYMPCA phase III trial reported median and OS benefits with ${ }^{223} \mathrm{Ra}$ compared with placebo in an interim analysis, which resulted in early trial stoppage because of efficacy (median survival, $14.9 \vee 11.3$ months; HR, 0.70 ; $95 \% \mathrm{CI}, 0.58$ to $0.83 ; P<$ .001). ${ }^{31}$ Enrollment criteria for this trial included men with $\geq$ two metastases to bone and excluded men with visceral metastases or lymphadenopathy $>3 \mathrm{~cm}$ in the short axis diameter. A majority of enrollees were using opiate analgesics at the time of enrollment. Modest QOL benefit was seen in favor of ${ }^{223} \mathrm{Ra}$, with $25 \%$ of patients experiencing meaningful improvements in QOL, compared with $16 \%$ in the placebo $\operatorname{arm}(P=.02)$. A dedicated pain assessment was not included in the trial. A subgroup analysis found lack of significant benefit in men with $<$ six metastases.

Sipuleucel-T. The IMPACT (Immunotherapy Prostate Adenocarcinoma Treatment) phase III trial reported a statistically significant 4.1-month median OS advantage with sipuleucel-T versus placebo (HR, $0.78 ; 95 \%$ CI, 0.61 to $0.98 ; P=.03) .{ }^{14}$ No significant differences were reported between treatment groups with regard to PSA response or objective disease progression. QOL was not reported. No statistically significant differences in grade 3 to 5 adverse events were reported (sipuleucel-T, 31.7\% $v$ placebo, 35.1\%; $P$ not reported). These efficacy results are consistent with a combined analysis of two smaller randomized trials reported previously. ${ }^{47}$

Therapies without definitive phase III data. Evidence for these therapies (ketoconazole, antiandrogens [eg, bicalutamide, flutamide, nilutamide], low-dose corticosteroid monotherapy) was previously evaluated as part of a separate ASCO systematic review of second-line 
hormonal therapies in CRPC. OS and QOL outcomes are not established, but there is evidence of activity for each and established mechanisms of action. In one phase III trial, the addition of ketoconazole to antiandrogen withdrawal produced greater PSA and objective responses than antiandrogen withdrawal alone, but no differences in OS, and $21 \%$ of patients experienced grade 3 or 4 adverse events. ${ }^{48}$ It is notable that this study was not powered to detect an OS end point, and crossover was allowed on progression. In a retrospective review of 138 patients started on low-dose ketoconazole (200 mg three times per day), $28 \%$ of patients had a PSA response. ${ }^{49}$ Fifty-five patients (40\%) subsequently received high-dose ketoconazole (400 mg three times per day); $13 \%$ of patients had an additional PSA response ( $P$ not reported). In general, high-dose ketoconazole was associated with a greater risk of adverse effects, and $11 \%$ of patients discontinued therapy because of adverse effects resulting from high-dose therapy. For patients who could not tolerate high-dose ketoconazole therapy, lowdose ketoconazole had similar efficacy.

In trials of bicalutamide versus diethylstilbestrol, ${ }^{50}$ prednisone versus flutamide, ${ }^{51}$ high- versus low-dose megestrol acetate, ${ }^{52}$ and dexamethasone versus megestrol acetate, ${ }^{53}$ there were no meaningful objective differences in outcome detected between treatment groups. In the prednisone-alone (10 mg per day) control arm of phase III clinical trial, PSA response was seen in $25 \%$ of patients, ${ }^{15}$ and a $28.8 \%$ pain response was seen with prednisone alone in the control arm of a different trial, ${ }^{54}$ although no placebo comparisons were included.

Negative trials and non-phase III trials. Clinical trials of several products have been conducted without evidence of overall benefit in clinically meaningful patient outcomes, including atrasentan, ${ }^{13,22}$ bevacizumab, ${ }^{21}$ calcitrol, $^{28,29}$ GVAX, ${ }^{26,27}$ orteronel, ${ }^{5,56}$ satraplatin, ${ }^{24}$ sunitinib, ${ }^{34}$ and zibotentan. ${ }^{30}$ Products have been tested alone or in addition to docetaxel. Of these, bevacizumab and sunitinib have been approved by regulatory authorities for other indications. The panel notes that although PFS did improve with some of these therapies, PFS is not an accepted surrogate end point in CRPC, and in the absence of demonstrated benefit in how patients feel, function, or survive, such improvement cannot be considered clinically meaningful. The panel also notes that results of a phase III trial of ipilimumab (after docetaxel) have been publicly reported, but not yet published, without demonstrated significant clinical benefit. Phase III results of a trial of tasquinimod and ipilumimab predocetaxel are not yet available. ${ }^{57}$

\section{Clinical Interpretation}

In the context of incurable metastatic cancer, it is the opinion of the panel that the goal of treatment is to provide the best possible QOL for as long as possible. Over the past decade, multiple therapies have become available for metastatic CRPC that provide OS benefit (although generally modest and measured in months), as well as QOL and pain benefits, demonstrated through well-designed phase III trials. Before that time, options were more limited, with unfavorable benefit-risk balance and limited quality evidence for most available therapies. In the contemporary selection of treatments, attention should be given to clinically meaningful benefit, risk of harm, quality of evidence, and cost when assisting patients with treatment decisions.

Some patients may reasonably opt against treatment because of toxicity or cost. ${ }^{58}$ Many of the therapies discussed in this guideline have high costs associated with them when compared historically with prior oncology drug products (Table 3), and out-of-pocket costs for patients can be considerable, leading to potential financial hardship.

\begin{tabular}{|c|c|c|c|}
\hline \multicolumn{4}{|c|}{$\begin{array}{l}\text { Table 3. Treatment Costs in Patients With CRPC for 30-Day Period } \\
\text { (oral drugs) or One Infusion/Cycle (parenteral drugs) }\end{array}$} \\
\hline Drug Name & $\begin{array}{l}\text { Approval } \\
\text { Date }\end{array}$ & $\begin{array}{l}\text { Large Group Commercial } \\
\text { Insurance Rate }(\$)^{*}\end{array}$ & $\begin{array}{l}\text { Medicare Rate } \\
(\$)^{*}\end{array}$ \\
\hline Abiraterone acetate & 2011 & $5,171.90$ & $6,409.11$ \\
\hline Bicalutamide & 1995 & Generic, 82; brand, 520 & $\begin{array}{l}\text { Generic, } 28 \\
\quad \text { brand, } 527\end{array}$ \\
\hline Cabazitaxel† & 2010 & $11,233.78$ & $12,806.06$ \\
\hline Degarelix & 2008 & 445.53 & 536.75 \\
\hline Docetaxelt & 1999 & $\begin{array}{l}\text { Brand (pregeneric), } \\
3,006.19\end{array}$ & $\begin{array}{l}\text { Generic, } \\
\quad 681.67\end{array}$ \\
\hline Enzalutamide & 2012 & $\neq$ & $7,906.34$ \\
\hline Flutamide & 1989 & 79.65 & 125.80 \\
\hline Goserelin acetate & 1995 & 596.00 & 210.32 \\
\hline Ketoconazole & 1999 & 66.52 & 19.22 \\
\hline Leuprolide acetate & 1998 & 356.00 & 202.84 \\
\hline Mitoxantrone† & 1987 & 615.63 & 203.96 \\
\hline Nilutamide & 1996 & 464.13 & $4,201.38$ \\
\hline Prednisone & 1974 & 3.75 & 6.50 \\
\hline Radium-223 & 2013 & $12,455.00 \ddagger$ & $12,455.00 \ddagger$ \\
\hline Sipuleucel-T§ & 2010 & $40,670.42$ & $34,672.58$ \\
\hline \multicolumn{4}{|c|}{$\begin{array}{l}\text { Abbreviations: CRPC, castration-resistant metastatic prostate cancer; } \\
\text { MSKCC, Memorial Sloan Kettering Cancer Center. } \\
\text { "Large group commercial rates were calculated using health care claims from } \\
\text { Truven Health Analytics MarketScan Commercial Claims and Encounters } \\
\text { database. }{ }^{59} \text { Calculation is based on total reimbursement for services rendered } \\
\text { based on most common supply of each product ( } 30 \text { days for most oral } \\
\text { medications or per infusion for injectable medications). } \\
\text { tIndicates regimen of every } 3 \text { weeks (sipuleucel-T and radium-223 are } \\
\text { limited-course therapies). Prices represent median dollars paid by both pa- } \\
\text { tients and insurers between } 2010 \text { and } 2011 \text { for each product use. Medicare } \\
\text { rates were calculated using methodology developed at Center for Health } \\
\text { Policy and Outcomes at MSKCC, }{ }^{60} \text { described by Bach et al. }{ }^{61} \text { For each oral } \\
\text { medication, } 2013 \text { full drug price was identified using the Medicare Plan Finder } \\
\text { tool. For each infused medication, dosage for original US Food and Drug } \\
\text { Administration-approved indication was used, and reimbursement rate was } \\
\text { taken from fourth-quarter } 2013 \text { average sales price files. Medicare rates are } \\
\text { standardized to monthly price. Price discrepancies between commercial } \\
\text { insurance and Medicare may represent differences in price between periods } \\
\text { (commercial, } 2010 \text { to } 2011 \text {; Medicare, } 2013 \text { ) or impact of generic entry on } \\
\text { price (eg, docetaxel). For infused medications, differences between per-use } \\
\text { and monthly price estimates may be evident, particularly for drugs adminis- } \\
\text { tered less frequently than every month (eg, goserelin acetate). Some products } \\
\text { are administered for limited set time periods (eg, sipuleucel-T, radium-223), } \\
\text { and prices represent fraction of total course cost during abbreviated period. } \\
\text { †Product not used during period when data were available. Prices for } \\
\text { radium-223 were obtained from MSKCC Web site, which were estimated } \\
\text { from media reports at time of last update. } \\
\$ S \text { Same as } † \text { footnote, but indicates regimen of every } 2 \text { weeks. }\end{array}$} \\
\hline
\end{tabular}

Cost-effectiveness assessment is not included in this guideline, but several of the discussed therapies have been found not to be cost effective by various authorities worldwide because of high cost relative to overall benefit.

Moreover, evidence demonstrates that many patients with incurable metastatic cancers believe that the goal of treatment is cure rather than palliation. ${ }^{62}$ Therefore, it is essential when discussing treatment options to determine the values and preferences of patients, communicate the goals of care, and clearly describe the benefits, harms, and financial impact of therapy options to the best of one's ability.

When added to androgen deprivation, there are three treatments for which there is strong evidence of survival as well as QOL benefit, with a favorable benefit-risk profile: abiraterone acetate, enzalutamide, and ${ }^{223} \mathrm{Ra}$ (for patients with predominantly bone metastases). Abiraterone acetate has been evaluated in men both before and after docetaxel chemotherapy. In a predocetaxel trial, multiple clinical end 
points were favorable, including pain and QOL, with a strong trend in favor of OS. In the postdocetaxel trial, statistically significant benefits in OS, pain, and QOL were seen. Enzalutamide has been evaluated favorably after docetaxel, with recently reported favorable results of a phase III trial in men before receiving docetaxel. ${ }^{38}$ Notably, patients in published phase III trials of abiraterone acetate and enzalutamide had not previously received the other agent, leaving open questions regarding sequencing or combinations of treatments, which are being evaluated in ongoing and planned trials. ${ }^{223}$ Ra was favorably evaluated in men who either received or did not receive prior docetaxel (phase III trial included patients who received, were not eligible to receive, or declined docetaxel, yielding $43 \%$ of participants who had not received prior docetaxel). OS was significantly improved, and although pain response was not explicitly evaluated as an end point, QOL measurement demonstrated overall benefit. A majority of men were receiving analgesics at baseline, suggesting that men with pain related to bone metastases are most likely to benefit from the palliative properties of ${ }^{223} \mathrm{Ra}$, although men without pain may also experience QOL benefit or delay in development of pain. Men with visceral metastases or lymphadenopathy $>3 \mathrm{~cm}$ were excluded, and a subgroup analysis found significant benefits restricted to men with $\geq$ six bone metastases, suggesting benefit is likely greatest among men for whom bone metastases, and not soft tissue disease, are the principal concern. The toxicity profile of ${ }^{223} \mathrm{Ra}$ is favorable when historically compared with other radiopharmaceuticals used in this population. It is not known whether combining ${ }^{223} \mathrm{Ra}$ with other treatments improves clinical outcomes. ${ }^{223} \mathrm{Ra}$ should be considered for patients with bone disease, whereas abiraterone or enzalutamide should be considered for those with bone and/or soft tissue disease. Use of any of these agents in combination should be restricted to the context of prospective clinical trials.

The distinction between pre- and postdocetaxel treatment contexts has been included in some clinical trials and regulatory review assessments, but the panel concludes that this distinction is of limited clinical usefulness when selecting treatment for an individual patient. Therefore, evidence of efficacy for agents was considered, regardless of relationship to prior chemotherapy, and the therapies discussed here are all considered to be reasonable choices for men who have or have not received docetaxel.

Docetaxel with prednisone remains an acceptable therapy to offer patients based on strong evidence of improved survival, pain, and overall QOL, but it has a relatively higher risk of toxicity when compared historically with abiraterone, enzalutamide, or ${ }^{223} \mathrm{Ra}$. Potential harms of this therapy should be discussed with patients at the time of decision making in relation to the apparently lower risk of harms associated with other options and to the patient's individual circumstances. If administered, docetaxel should be given every 3 weeks, which has been shown to be superior to a once-per-week schedule. Results of a phase III trial among men with newly diagnosed metastatic androgen-sensitive prostate cancer suggest a substantial survival benefit when adding docetaxel chemotherapy to androgen-deprivation therapy. ${ }^{45,63}$ At the time of this guideline update, these results are available only as a meeting presentation and not yet published.

Sipuleucel-T has been reported to significantly improve OS among men who are asymptomatic or mildly symptomatic (ie, have mild pain related to prostate cancer). Impact on QOL was not formally studied. Risks of harm are relatively low. Although con- troversies have been raised in editorials regarding the conduct of clinical research of this product, based on the trial results, it remains an option that may reasonably be discussed with patients who have a low symptom burden.

Cabazitaxel with prednisone, when administered to men who have received prior docetaxel, offers a statistically significant OS benefit, although it does not seem to substantially improve pain; impact on QOL is not known, but it carries a substantial toxicity profile. Although pain results seemed similar to those in the mitoxantrone control arm of the phase III trial, those response rates were substantially lower than in the initial phase III mitoxantrone trial. Cabazitaxel with prednisone may be offered to men who have received prior therapies involving a more favorable benefit-risk profile, accompanied by a discussion of the risk of harms.

Mitoxantrone offers no demonstrated survival benefit. Although initial research in the 1990 s reported a pain response rate of $29 \%$, more recent evaluation in a more heavily pretreated population found only a $7.7 \%$ pain response rate. Given the high risk of toxicity, mitoxantrone may be less attractive to patients. This therapy may be commercially available where others are not and is generally less costly. If offered to patients, it should be accompanied by a discussion of the clinical benefits and risk of harms.

There are limited data regarding the clinical benefits of older antiandrogens (eg, bicalutamide, flutamide, nilutamide), ketoconazole, and prednisone. Antiandrogens carry relatively few toxicities and vary in cost. Ketoconazole carries higher adverse effects and is relatively inexpensive. These products are less efficacious than more recently developed drugs with similar mechanisms, but they may be more accessible for some patients and in low-resource contexts. These drugs may be considered particularly for patients with lower disease burden or limited other options, accompanied by a discussion of the unclear clinical benefits and potential toxicities.

Prednisone monotherapy at a low dose (eg, $10 \mathrm{mg}$ per day) seems to have activity in CRPC, may be particularly beneficial for pain palliation (eg, as seen in control arms of abiraterone acetate controlled trials), and is inexpensive, although its effects on survival are not known.

\section{RECOMMENDATIONS}

These recommendations were developed based on systematic reviews of the scientific literature and expert panel consensus, based on the best available evidence and clinical experience as a guide. They are evidence based and informed by RCT data. Summary descriptions of results are provided in the literature review and analysis section and are presented fully in the systematic review of the literature. ${ }^{7}$ Ratings for the type of recommendation and strength of the evidence are offered (Methodology Supplement provides rating definitions).

These guideline recommendations were crafted, in part, using the Guidelines Into Decision Support (GLIDES) methodology and accompanying BRIDGE-Wiz software ${ }^{64}$ (Methodology Supplement). A guideline implementability review was conducted to improve clarity around recommended actions for clinical practice. Details of the implementation review are provided in the Appendix (online only). 


\section{PATIENT AND CLINICIAN COMMUNICATION}

Patients should be fully informed about the extent of potential benefit as well as harm and cost of treatment before making decisions. ASCO and CCO consider it essential to good clinical practice to assure that this information and the goals of care are understood.

Many patients misunderstand the goals of care in the setting of metastatic disease to be curative rather than palliative. This may lead to decisions to accept excess toxicity or cost based on incorrect assumptions about potential benefit. Palliative care should be offered to all patients, particularly to those exhibiting symptoms or QOL decrements, and is recommended in a separate ASCO document. ${ }^{65}$

\section{HEALTH DISPARITIES}

Although ASCO clinical practice guidelines represent expert recommendations on the best practices in disease management to provide the highest level of cancer care, it is important to note that many patients have limited access to medical care. Economic and racial/ ethnic disparities in health care contribute significantly to this problem. Patients with cancer in these populations have been shown in many cases to suffer disproportionately from comorbidities, experience more substantial obstacles to receiving care, to be more likely to be uninsured, and to be at greater risk of receiving lower quality care. Many patients lack access to care because of geographic distance from treatment facilities. Awareness of these disparities in access to care should be considered in the context of this clinical practice guideline, and health care providers should make extra efforts to deliver the highest level of cancer care possible to these vulnerable populations. Moreover, efforts are encouraged to enroll patient populations onto clinical trials that are representative of the diversity of treated patients in the community.

\section{MULTIPLE CHRONIC CONDITIONS}

Creating evidence-based recommendations to inform treatment of patients with additional chronic conditions, a situation in which the patient may have $\geq$ two such conditions_-referred to as multiple chronic conditions (MCCs) - is challenging. Patients with MCCs are a complex and heterogeneous population, making it difficult to account for all of the possible permutations to develop specific recommendations for care. In addition, the best available evidence for treating index conditions, such as cancer, is often from clinical trials, the study selection criteria of which may exclude these patients to avoid potential interaction effects or confounding of results associated with MCCs. As a result, the reliability of outcome data from these studies may be limited, thereby creating constraints for expert groups to make recommendations for care in this heterogeneous patient population.

Because many patients for whom guideline recommendations apply present with MCCs, any treatment plan needs to take into account the complexity and uncertainty created by the presence of MCCs and highlight the importance of shared decision making regarding guideline use and implementation. Therefore, in consideration of recommended care for the target index condition, the clinician should review all other chronic conditions present in the patient and take those conditions into account when formulating treatment and follow-up plans.

In light of these considerations, practice guidelines should provide information on how to apply the recommendations for patients with MCCs, perhaps as a qualifying statement for recommended care. This may mean that some or all of the recommended care options are modified or not applied, as determined by best practice in consideration of any MCC.

For men with prostate cancer age $<65$ years, the 10 most common comorbid conditions are hypertension, hyperlipidemia, diabetes, ischemic heart disease, anemia, arthritis, chronic kidney disease, depression, chronic obstructive pulmonary disease, and heart failure. For men with prostate cancer age $>65$ years, the 10 most common comorbidities are hypertension, hyperlipidemia, ischemic heart disease, anemia, diabetes, arthritis, chronic kidney disease, cataract, heart failure, and chronic obstructive pulmonary disease. Presence of any of these comorbid conditions should be taken into account when deciding on an individual treatment plan. Please refer to the table in the Data Supplement for details on the number of patients affected by these comordid conditions and other supplementary information.

\section{COST IMPLICATIONS}

As discussed previously and detailed in Table 3, some of the treatments available in this setting are associated with considerable cost, and some patients may decide against some treatments because of this. ${ }^{58} \mathrm{Al}$ though a cost-effectiveness assessment is not included in this guideline, several of the discussed therapies have been found not to be cost effective by various authorities worldwide because of high cost relative to overall benefit.

\section{EXTERNAL REVIEW}

A draft of the clinical practice guideline was reviewed by 14 practitioner content experts from the United States $(\mathrm{n}=8)$ and Canada $(\mathrm{n}=$ 6). Reviewers were asked in a structured questionnaire to rate the quality of the guideline and whether they would make use of the guideline and recommend it to others. They were asked for their assessment of the barriers or enablers to implementation. This guideline was rated as high quality, and overall, practitioners agreed that the guideline would be of use in their own professional decisions, as well as in general clinical practice.

Identified barriers included recommending agents not available in Canada, cost and funding of agents, controversy around the use of sipuleucil-T as a standard option, and timing of initiation of additional therapies. To address this feedback, the recommendations were restructured to allow for greater consideration of health setting and drug availability and broader context on the use of sipuleucil-T, with references provided. Detailed results of the external review are available on the CCO Web site at https://www.cancercare.on.ca/toolbox/ qualityguidelines/diseasesite/genito-ebs/.

\section{GUIDELINE IMPLEMENTATION}

ASCO guidelines are developed for implementation across health settings. Barriers to implementation include the need to increase 
awareness of the guideline recommendations among front-line practitioners and survivors of cancer and caregivers, as well as the need to provide adequate services in the face of limited resources. The guideline Bottom Line Box was designed to facilitate implementation of recommendations. This guideline will be distributed widely throughout the ASCO Practice Guideline Implementation Network (Appendix Table A2, online only). ASCO guidelines are posted on the ASCO Web site and most often published in JCO and Journal of Oncology Practice.

\section{LIMITATIONS OF RESEARCH AND FUTURE DIRECTIONS}

There is limited available evidence in the following areas of needed research in metastatic CRPC:

- Optimum sequencing and combination of available therapies

- Efficacy of drugs in treatment sequences other than those tested in clinical trials

- Potential benefits and harms of combining therapies

- Comparative QOL and symptomatic benefits of therapy options

- Effectiveness of therapies in real-world populations

- Cost-benefit analysis in the US context

- Out-of-pocket costs faced by most patients

- Shared decision-making tools

- Clinical benefits of lower-cost therapies in lowresource contexts

- Impact of early access to palliative care

- Alternative approaches to continuous androgen deprivation The panel recommends inclusion of rigorously designed symptom and QOL outcome measures in all phase III clinical trials in metastatic CRPC. ASCO believes that cancer clinical trials are vital to inform medical decisions and improve cancer care and that all patients should have the opportunity to participate.

\section{ADDITIONAL RESOURCES}

Data Supplements, including evidence tables, and clinical tools and resources can be found at www.asco.org/guidelines/mCRPC. Patient information is available there and at www.cancer.net.
AUTHORS' DISCLOSURES OF POTENTIAL CONFLICTS OF INTEREST

Although all authors completed the disclosure declaration, the following author(s) and/or an author's immediate family member(s) indicated a financial or other interest that is relevant to the subject matter under consideration in this article. Certain relationships marked with a " $U$ " are those for which no compensation was received; those relationships marked with a "C" were compensated. For a detailed description of the disclosure categories, or for more information about ASCO's conflict of interest policy, please refer to the Author Disclosure Declaration and the Disclosures of Potential Conflicts of Interest section in Information for Contributors. Employment or Leadership Position: None Consultant or Advisory Role: Ethan Basch, Exelixis (U); D. Andrew Loblaw, AstraZeneca (C), Roche (C), sanofi-aventis (C), GlaxoSmithKline (C), Merck (C), Amgen (C), Astellas Pharma (C), Janssen (C), GE Health Care (C); Michael Carducci, sanofi-aventis (C), Medivation (C), Astellas Pharma (C), Amgen (C); Sebastien Hotte, Janssen (C), Astellas Pharma (C); Michael Kattan, Merck (C), GlaxoSmithKline (C); Derek Raghavan, sanofi-aventis (C); Fred Saad, sanofi-aventis (C), Astellas Pharma (C), Janssen (C), Bayer HealthCare Pharmaceuticals (C), Amgen (C), Abbvie (C); Mary-Ellen Taplin, Dendreon (C), Medivation (C), sanofi-aventis (C), Janssen (C), Tokai (C), Bayer HealthCare Pharmaceuticals (C) Stock Ownership: None Honoraria: D. Andrew Loblaw, AstraZeneca, sanofi-aventis, Amgen, Elekta, GE Health Care, Janssen, Paladin; Sebastien Hotte, Janssen, Astellas Pharma; Fred Saad, sanofi-aventis, Janssen, Astellas Pharma, Bayer HealthCare Pharmaceuticals, Amgen, Abbvie; Mary-Ellen Taplin, Cowan, Guide Point Global Research Funding: D. Andrew Loblaw, sanofi-aventis, Paladin; Michael Kattan, Dendreon; Fred Saad, Medivation, sanofi-aventis, Astellas Pharma, Janssen, Bayer HealthCare Pharmaceuticals, Oncogenex; Mary-Ellen Taplin, Genentech, Medivation, Janssen Expert Testimony: None Patents, Royalties, and Licenses: James N. Frame, royalties as co-editor of Hematology Oncology Therapy by McGraw Hill Other Remuneration: D. Andrew Loblaw, Janssen, Paladin

\section{AUTHOR CONTRIBUTIONS}

Administrative support: Thomas K. Oliver, Cindy Walker-Dilks, R. Bryan Rumble

Manuscript writing: All authors

Final approval of manuscript: All authors

\section{REFERENCES}

1. American Cancer Society: Cancer Facts and Figures 2011. http://www.cancer.org/acs/groups/content/ @epidemiologysurveilance/documents/document/ acspc-029771.pdf

2. Advisory Committee on Cancer Statistics: $\mathrm{Ca}$ nadian Cancer Statistics 2013. Toronto, Ontario, Canada, Canadian Cancer Society, 2013

3. Loblaw DA, Virgo KS, Nam R, et al: Initial hormonal management of androgen-sensitive metastatic, recurrent, or progressive prostate cancer: 2007 update of an American Society of Clinical Oncology practice guideline. J Clin Oncol 25:1596-1605, 2007

4. Smith MR, Kabbinavar F, Saad F, et al: Natural history of rising serum prostate-specific antigen in men with castrate nonmetastatic prostate cancer. J Clin Oncol 23:2918-2925, 2005

5. Winquist $E$, Waldron $T$, Berry $S$, et al: Nonhormonal systemic therapy in men with hormone- refractory prostate cancer and metastases: A systematic review from the Cancer Care Ontario Program in Evidence-Based Care's Genitourinary Cancer Disease Site Group. BMC Cancer 6:112, 2006

6. Basch EM, Somerfield MR, Beer TM, et al: American Society of Clinical Oncology endorsement of the Cancer Care Ontario Practice guideline on nonhormonal therapy for men with metastatic hormone-refractory (castration-resistant) prostate cancer. J Clin Oncol 25:5313-5318, 2007

7. Galsky MD, Vogelzang NJ: Docetaxel-based combination therapy for castration-resistant prostate cancer. Ann Oncol 21:2135-2144, 2010

8. Loblaw DA, Walker-Dilks $C$, Winquist $E$, et al: Systemic therapy in men with metastatic castrationresistant prostate cancer: A systematic review. Clin Oncol (R Coll Radiol) 25:406-430, 2013

9. Nelson JB, Fizazi K, Miller K, et al: Phase 3, randomized, placebo-controlled study of zibotentan (ZD4054) in patients with castration-resistant pros- tate cancer metastatic to bone. Cancer 118:57095718, 2012

10. James ND, Caty A, Payne H, et al: Final safety and efficacy analysis of the specific endothelin $A$ receptor antagonist zibotentan (ZD4054) in patients with metastatic castration-resistant prostate cancer and bone metastases who were pain-free or mildly symptomatic for pain: A double-blind, placebocontrolled, randomized phase II trial. BJU Int 106: 966-973, 2010

11. Pili R, Häggman M, Stadler WM, et al: Phase II randomized, double-blind, placebo-controlled study of tasquinimod in men with minimally symptomatic metastatic castrate-resistant prostate cancer. J Clin Oncol 29:4022-4028, 2011

12. Armstrong AJ, Häggman $M$, Stadler WM, et al: Long-term survival and biomarker correlates of tasquinimod efficacy in a multicenter randomized study of men with minimally symptomatic metastatic castration-resistant prostate cancer. Clin Cancer Res 19:6891-6901, 2013 
13. Carducci MA, Saad F, Abrahamsson PA, et al: A phase 3 randomized controlled trial of the efficacy and safety of atrasentan in men with metastatic hormone-refractory prostate cancer. Cancer 110: 1959-1966, 2007

14. Kantoff PW, Higano CS, Shore ND, et al: Sipuleucel-T immunotherapy for castration-resistant prostate cancer. N Engl J Med 363:411-422, 2010

15. Ryan CJ, Smith MR, de Bono JS, et al: Abiraterone in metastatic prostate cancer without previous chemotherapy. N Engl J Med 368:138-148, 2013

16. Beer TM, Armstrong AJ, Sternberg CN, et al: Enzalutamide in men with chemotherapy-naive met astatic prostate cancer (mCRPC): Results of phase III PREVAIL study. J Clin Oncol 32, 2014 (suppl 4; abstr LBA1)

17. Kellokumpu-Lehtinen $\mathrm{PL}$, Harmenberg U, Joensuu T, et al: 2-Weekly versus 3-weekly docetaxel to treat castration-resistant advanced prostate cancer: A randomised, phase 3 trial. Lancet Oncol 14:117-124, 2013

18. Berthold DR, Pond GR, Soban F, et al: Docetaxel plus prednisone or mitoxantrone plus prednisone for advanced prostate cancer: Updated survival in the TAX 327 study. J Clin Oncol 26:242245, 2008

19. Fosså $S D$, Jacobsen $A B$, Ginman $C$, et al: Weekly docetaxel and prednisolone versus prednisolone alone in androgen-independent prostate cancer: A randomized phase II study. Eur Urol 52: 1691-1699, 2007

20. Machiels JP, Mazzeo F, Clausse M, et al: Prospective randomized study comparing docetaxel, estramustine, and prednisone with docetaxel and prednisone in metastatic hormone-refractory prostate cancer. J Clin Oncol 26:5261-5268, 2008

21. Kelly WK, Halabi $S$, Carducci $M$, et al: Randomized, double-blind, placebo-controlled phase III trial comparing docetaxel and prednisone with or without bevacizumab in men with metastatic castration-resistant prostate cancer: CALGB 90401. J Clin Oncol 30:1534-1540, 2012

22. Quinn DI, Tangen CM, Hussain $M$, et al: Docetaxel and atrasentan versus docetaxel and placebo for men with advanced castration-resistan prostate cancer (SWOG S0421): A randomised phase 3 trial. Lancet Oncol 14:893-900, 2013

23. Sonpavde G, Matveev VB, Burke JM, et al: A randomized, double-blind phase II trial of docetaxel plus prednisone (DP) combined with either AT-101 or placebo for the first-line therapy of metastatic castration-resistant prostate cancer (CRPC). J Clin Oncol 29:295s, 2011 (suppl; abstr 4528)

24. Sternberg CN, Dumez H, Van Poppel H, et al: Docetaxel plus oblimersen sodium (Bcl-2 antisense oligonucleotide): An EORTC multicenter, randomized phase II study in patients with castrationresistant prostate cancer. Ann Oncol 20:1264-1269, 2009

25. Mathew $P$, Thall PF, Bucana $C D$, et al: Platelet-derived growth factor receptor inhibition and chemotherapy for castration-resistant prostate cancer with bone metastases. Clin Cancer Res 13:5816-5824, 2007

26. Higano C, Saad F, Somer B, et al: A phase III trial of GVAX immunotherapy for prostate cancer versus docetaxel plus prednisone in asymptomatic, castration-resistant prostate cancer (CRPC). J Clin Oncol 27, 2009 (suppl; abstr LBA150)

27. Small E, Demkow T, Gerritsen $W$, et al: A phase III trial of GVAX immunotherapy for prostate cancer in combination with docetaxel versus docetaxel plus prednisone in symptomatic, castration- resistant prostate cancer (CRPC). J Clin Oncol 27, 2009 (suppl; abstr 7)

28. Scher HI, Jia X, Chi $K$, et al: Randomized, open-label phase III trial of docetaxel plus high-dose calcitriol versus docetaxel plus prednisone for patients with castration-resistant prostate cancer. J Clin Oncol 29:2191-2198, 2011

29. Beer $T$, Ryan $C$, Venner $P$, et al: Doubleblinded randomized study of high-dose calcitriol plus docetaxel in androgen-independent prostate cancer: A report from ASCENT investigators. J Clin Oncol 25:669-674, 2007

30. Fizazi KS, Higano CS, Nelson JB, et al: Phase III, randomized, placebo-controlled study of docetaxel in combination with zibotentan in patients with metastatic castration-resistant prostate cancer. J Clin Oncol 31:1740-1747, 2013

31. Parker C, Nilsson S, Heinrich D, et al: Alpha emitter radium-223 and survival in metastatic prostate cancer. N Engl J Med 369:213-223, 2013

32. de Bono J, Oudard S, Ozguroglu M, et al: Prednisone plus cabazitaxel or mitoxantrone for metastatic castration-resistant prostate cancer progressing after docetaxel treatment: A randomised open-label trial. Lancet 376:1147-1154, 2010

33. Sternberg CN, Petrylak DP, Sartor $O$, et al: Multinational, double-blind, phase III study of prednisone and either satraplatin or placebo in patients with castrate-refractory prostate cancer progressing after prior chemotherapy: The SPARC trial. J Clin Oncol 27:5431-5438, 2009

34. Ou Y, Michaelson M, Sengeløv $L$, et al: Randomized, placebo-controlled, phase III trial of sunitinib in combination with prednisone $(\mathrm{SU}+\mathrm{P})$ versus prednisone $(\mathrm{P})$ alone in men with progressive metastatic castration-resistant prostate cancer (mCRPC). J Clin Oncol 29:292s, 2011 (suppl; abstr 4515)

35. Scher HI, Fizazi K, Saad F, et al: Increased survival with enzalutamide in prostate cancer after chemotherapy. N Engl J Med 367:1187-1197, 2012

36. Fizazi K, Scher HI, Molina A, et al: Abiraterone acetate for treatment of metastatic castrationresistant prostate cancer: Final overall survival analysis of the COU-AA-301 randomised, double-blind, placebo-controlled phase 3 study. Lancet Oncol 13:983-992, 2012

37. de Bono JS, Logothetis CJ, Molina A, et al: Abiraterone and increased survival in metastatic prostate cancer. N Engl J Med 364:1995-2005, 2011

38. Beer TM, Armstrong AJ, Rathkopf DE, et al: Enzalutamide in metastatic prostate cancer before chemotherapy. N Engl J Med [epub ahead of print on June 1, 2014]

39. Mohler JL, Armstrong AJ, Bahnson RR, et al: Prostate cancer, version 3.2012 featured updates to the NCCN guidelines. J Natl Compr Canc Netw 10:1081-1087, 2012

40. Cookson MS, Roth BJ, Dahm $P$, et al: Castration-resistant prostate cancer: AUA guideline. J Urol 190:429-438, 2013

41. Bahl A, Oudard S, Tombal B, et al: Impact of cabazitaxel on 2-year survival and palliation of tumour-related pain in men with metastatic castration-resistant prostate cancer treated in the TROPIC trial. Ann Oncol 24:2402-2408, 2013

42. Exelixis: Study of cabozantinib (XL184) versus mitoxantrone plus prednisone in men with previously treated symptomatic castration-resistant prostate cancer (COMET-2). www.clinicaltrials.gov/ct2/ show/NCT01522443

43. Harland S, Staffurth J, Molina A, et al: Effect of abiraterone acetate treatment on the quality of life of patients with metastatic castration-resistant prostate cancer after failure of docetaxel chemotherapy. Eur J Cancer 49:3648-3657, 2013

44. Sternberg CN, Molina A, North S, et al: Effect of abiraterone acetate on fatigue in patients with metastatic castration-resistant prostate cancer after docetaxel chemotherapy. Ann Oncol 24:1017-1025, 2013

45. Sweeney $\mathrm{C}$, Chen $\mathrm{YH}$, Carducci MA, et al: Impact on overall survival (OS) with chemohormonal therapy versus hormonal therapy for hormonesensitive newly metastatic prostate cancer ( $\mathrm{mPrCa}$ ): An ECOG-led phase III randomized trial. J Clin Oncol 32, 2014 (suppl 15s; abstr LBA2)

46. Tannock IF, Osoba D, Stockler MR, et al: Chemotherapy with mitoxantrone plus prednisone or prednisone alone for symptomatic hormoneresistant prostate cancer: A Canadian randomized trial with palliative end points. J Clin Oncol 14:17561764, 1996

47. Higano CS, Schellhammer PF, Small EJ, et al: Integrated data from 2 randomized, double-blind, placebo-controlled, phase 3 trials of active cellular immunotherapy with sipuleucel-T in advanced prostate cancer. Cancer 115:3670-3679, 2009

48. Small EJ, Halabi S, Dawson NA, et al: Antiandrogen withdrawal alone or in combination with ketoconazole in androgen-independent prostate cancer patients: A phase III trial (CALGB 9583). $\mathrm{J}$ Clin Oncol 22:1025-1033, 2004

49. Nakabayashi M, Xie W, Regan MM, et al: Response to low-dose ketoconazole and subsequent dose escalation to high-dose ketoconazole in patients with androgen-independent prostate cancer. Cancer 107:975-981, 2006

50. Manikandan R, Srirangam SJ, Pearson E, et al: Diethylstilboestrol versus bicalutamide in hormone refractory prostate carcinoma: A prospective randomized trial. Urol Int 75:217-221, 2005

51. Fosså SD, Slee $P H$, Brausi $M$, et al: Flutamide versus prednisone in patients with prostate cancer symptomatically progressing after androgen-ablative therapy: A phase III study of the European Organisation for Research and Treatment of Cancer genitourinary group. J Clin Oncol 19:62-71, 2001

52. Dawson NA, Conaway M, Halabi S, et al: A randomized study comparing standard versus moderately high dose megestrol acetate for patients with advanced prostate carcinoma: Cancer and Leukemia Group B study 9181. Cancer 88:825-834, 2000

53. Patel SR, Kvols LK, Hahn RG, et al: A phase II randomized trial of megestrol acetate or dexamethasone in the treatment of hormonally refractory advanced carcinoma of the prostate. Cancer 66:655658, 1990

54. Logothetis CJ, Basch E, Molina A, et al: Effect of abiraterone acetate and prednisone compared with placebo and prednisone on pain control and skeletal-related events in patients with metastatic castration-resistant prostate cancer: Exploratory analysis of data from the COU-AA-301 randomised trial. Lancet Oncol 13:1210-1217, 2012

55. De Wit R, Fizazi K, Jinga V, et al: Phase 3, randomized, placebo-controlled trial of northern (TAK-700) plus prednisone in patients (pts) with chemotherapy-naïve metastatic castration-resistant prostate cancer (mCRPC) (ELM-PC 4 trial). J Clin Oncol 32, 2014 (suppl 15s; abstr 5008)

56. Dreicer $R$, Jones $R$, Oudard $S$, et al: Results from a phase 3 , randomized, double-blind, multicenter, placebo-controlled trial of orteronel (TAK700) plus prednisone in patients with metastatic castration-resistant prostate cancer (mCRPC) that has progressed during or following docetaxel-based 
therapy (ELM-PC 5 trial). J Clin Oncol 32, 2014 (suppl 4; abstr 7)

57. Active Biotech $A B$ : A study of tasquinimod in men with metastatic castrate resistant prostate cancer. www.clinicaltrials.gov/ct2/show/NCT01234311

58. Zafar SY, Peppercorn JM, Schrag D, et al: The financial toxicity of cancer treatment: A pilot study assessing out-of-pocket expenses and the insured cancer patient's experience. Oncologist 18:381-390, 2013

59. Truven Health Analytics: Life Sciences. http:// www.truvenhealth.com/your_healthcare_focus/ pharmaceutical_and_medical_device/data_ databases_and_online_tools.aspx
60. Memorial Sloan Kettering Cancer Center: Cost of Cancer Drugs. http://www.mskcc.org/research/healthpolicy-outcomes/cost-drugs

61. Bach PB, Limits on Medicare's ability to control rising spending on cancer drugs. N Engl J Med 360:626-633, 2009

62. Weeks JC, Catalano PJ, Cronin A, et al: Patients' expectations about effects of chemotherapy for advanced cancer. N Engl J Med 367:1616-1625, 2012

63. National Institutes of Health: $\mathrm{NIH}$-funded study shows increased survival in men with metastatic prostate cancer who receive chemotherapy when starting hormone therapy. http://www .nih.gov/news/health/dec2013/nci-05.htm

64. Shiffman RN, Michel G, Rosenfeld RM, et al: Building better guidelines with BRIDGE-Wiz: Development and evaluation of a software assistant to promote clarity, transparency, and implementability. J Am Med Inform Assoc 19:94-101, 2012

65. Smith TJ, Temin S, Alesi ER, et al: American Society of Clinical Oncology provisional clinical opinion: The integration of palliative care into standard oncology care. J Clin Oncol 30:880-887, 2012

\section{Affiliations}

Ethan Basch, Ronald C. Chen, and Stacie B. Dusetzina, University of North Carolina, Chapel Hill; Derek Raghavan, Carolinas Health Care/Levine Cancer Institute, Charlotte, NC; D. Andrew Loblaw, Odette Cancer Centre, Sunnybrook Health Sciences Centre; Ted Wootton, Patient Representatives, Toronto; Sebastian Hotte and Cindy Walker-Dilks, McMaster University; Cindy Walker-Dilks, Cancer Care Ontario, Hamilton; Eric Winquist, London Health Sciences Centre, London, Ontario; Fred Saad, University of Montreal, Montreal, Quebec, Canada; Thomas K. Oliver and R. Bryan Rumble, American Society of Clinical Oncology, Alexandria, VA; Michael Carducci, Johns Hopkins University, Baltimore, MD; James N. Frame, Charleston Area Medical Center Health Systems, Charleston, WV; Kristina Garrels, Private Practice, Fargo, ND; Michael W. Kattan, Cleveland Clinic, Cleveland, OH; Mary-Ellen Taplin, Dana-Farber Cancer Institute, Boston, MA; James Williams, Pennsylvania Prostate Cancer Coalition, Camp Hill, PA; Charles L. Bennett, South Carolina College of Pharmacy, Columbia, SC; and Katherine S. Virgo, Emory University, Atlanta, GA. 


\section{Acknowledgment}

We thank members of the Cancer Care Ontario (CCO) Genitourinary Disease Site Group and CCO Report Approval Panel and Melissa Brouwers, PhD, Bill Evans, MD, and Marko Simunovic, MD, MPH, for their reviews and approval of the guideline. We also thank the American Society of Clinical Oncology (ASCO) Clinical Practice Guidelines Committee, particularly Scott Gilbert, MD, and Michael Danso, MD, for review and approval of the guideline and James N. Frame, MD, for his review on behalf of the ASCO Practice Guideline Implementation Network. Additionally, we thank the 14 US and Canadian external reviewers who provided detailed content review and ratings of the guideline content.

\section{Appendix}

\section{Guideline Implementability Review}

1. Please indicate your contact information.

2. Is it clear for which patients and at what time one would use these recommendations?

(1) Very clear $(\mathrm{X})$

(2) ()

(3) Neutral ()

(4) ()

(5) Very unclear ()

Comment: The choice of agents and their prioritization ("should offer," "may offer") are clearly defined in the prechemotherapy setting, upon initiation of chemotherapy, and in the postchemotherapy setting. The manuscript discusses sufficiently the lack of data on agent sequencing (ie, postdocetaxel setting) while providing a useful contextual discussion on this issue in the section on Clinical Interpretation of Evidence.

3. Is it clear what action(s) the practitioner(s) should take (or not take), based on the recommendation(s)?
(1) Very clear $(\mathrm{X})$
(2) ()
(3) Neutral ()
(4) ()
(5) Very unclear ()

Comment: The recommendations provided in the Bottom Line are focused and well written, as are the clarifying statements, as to what the guideline does not cover or recommend and the lack of data to guide agent sequencing. The section on Clinical Considerations compliments the recommendations.

4. Does the recommendation(s) have enough detail for people with various professional backgrounds (eg, physician extenders, pharmacists) who might implement the recommendation(s)?

(1) Too much detail ()

(2) ()

(3) Sufficient detail (X)

(4) ()

(5) Insufficient detail ()

Comment: Under the supervision of a treating oncologist, there are sufficient guideline details and patient population caveats to permit the guidance of physician extenders and pharmacists involved in the implementation of these guidelines. The manuscript also directs clinicians to review the papers from which these guidelines are derived for additional information relevant to clinical care considerations.

5. Would there be consistency in the interpretation and execution of these recommendations among your colleagues?

(1) Yes $(\mathrm{X})$

(2) ()

(3) Neutral ()

(4) ()

(5) No ()

Comment: The chances are high for consistency in the interpretation and execution of recommendations in the context of "treatment settings" as defined in the manuscript. However, within the pre- and postchemotherapy settings (the latter, in particular) there may be variability in agent selection based on physician preference. There is sufficient flexibility in the guidelines to permit agent selection that may be offered based on patient characteristics and shared decision making.

6. Are actions implementable under current conditions (eg, FDA [US Food and Administration] approval, drug availability)? (Recommendation may be either "aspirational" or implementable, but it is suggested that panels be explicit.)

(1) Very $(\mathrm{X})$

(2) () 
(3) Neutral ()

(4) ()

(5) Not at all ()

Comment: The agents that "should" or "may" be recommended in the Bottom Line are currently FDA approved for this patient population. Please see additional comments in Question 11.

7. Will providers think the recommendation is novel or unconventional?
(1) Yes ()
(2) ()
(3) Neutral ()
(4) ()
(5) No (X)

Comment: The recommendations outlined in the Bottom Line are evidence based, and the discussion of these agents, as well as those that are not recommended, is well critiqued in the manuscript. I believe the reviewed agents/trials and methodologies described in the manuscript are sufficiently rigorous and balanced as to preclude being considered novel or unconventional approaches to guideline derivation. The pilot effort using GLIDES [Guidelines Into Decision Support] and BRIDGE-Wiz is helpful in providing clarifying language for guideline implementation.

8. Are the recommendation(s) sufficiently flexible to allow different providers to implement it/them?

(1) Too flexible ()

(2) ()

(3) Sufficient (X)

(4) ()

(5) Insufficient ()

Comment: They are sufficiently flexible. Also see my comments in Question 5.

9. Could a practice implement the recommendations now or would a practice need new recommendations (please check all that may apply)?

Knowledge/skills

Other, please specify

Comment: My comment in this section relates to sipuleucel-T. For the use of sipuleucel-T, the practice would need to be familiar with the unique logistical aspects in having this product available for their patients but I do not see this as a barrier to implementation in a modern oncology practice. An oncology practice can implement the recommendations in this guideline.

10. Is the guideline similarly applicable to different types of practices including solo and small groups, large independent groups, and hospital-based providers? If you answered "not at all applicable," please identify specific barriers for specific practice setting(s).

(1) Very applicable $(\mathrm{X})$

(2) ()

(3) Neutral ()

(4) ()

(5) Not at all applicable ()

11. Are there currently payer restrictions of any kind that could limit implementation (eg, use of off-label drugs)?

Comment: No. The recommended agents in the Bottom Line are FDA approved for the treatment of CRPC [castration-resistant prostate cancer] in the described settings. However, my response would be "yes" to comments relative to "select" or "highly selected" patients who may be offered bevacizumab or sunitinib, respectively, in which neither agent is FDA approved for the treatment of CRPC. 12. Are there aspects of the recommendation(s) that may be unacceptable to your patients (eg, unacceptable risk, unacceptable cost, perceived marginal benefit)?

(1) Yes ()

(2) ()

(3) Neutral ()

(4) $(\mathrm{X})$

(5) No ()

Comment: In general, no. The recommendations are sound and based on quality RCT [randomized controlled trial] evidence. I have had a small population of patients (in whom this guideline would apply) decline some of these agents based on cost and/or co-pays and sometimes based on their own perceptions of benefit. I do not see this circumstance being altered by the current set of guidelines. However, the majority of patients with an acceptable PS [performance status] in whom I have this treatment discussion elect treatment and would find this guideline helpful (but I still refer them to our financial navigator). The manuscript is very clear in having an open conversation with patients regarding the harms and benefits of therapy and in a fashion consistent with shared decision making. 
13. Are the recommendation(s) sufficiently flexible to allow different patients (eg, comorbidities, ages) to receive care based on it?

(1) Too flexible ()

(2) ()

(3) Sufficient $(\mathrm{X})$

(4) ()

(5) Insufficient ()

Comment: The sections devoted to Qualifying Statements, Clinical Considerations, and Interpretation of Evidence provide opportunities to have very practical and realistic guideline discussions with our patients. Within the various described treatment settings, the GLIDES methodology and BRIDGE-Wiz software permit clarifying language relative to agent(s) that "should" or "may be" offered. 14. Are there particular recommendations for which you see large barriers to implementation?

Comment: No. Of the recommendations provided in the Bottom Line, I see no large barriers to implementation. For the comments related to the use of bevacizumab or sunitinib in "select" or "highly selected" patients, I see large barriers within the United States as these agents are not currently FDA approved for the treatment of CRPC.

15. Is this a useful set of recommendations?

(1) Yes $(\mathrm{X})$

(2) ()

(3) Neutral ()

(4) ()

(5) No ()

16. Will this set of recommendations assist you in the care of your patients in your practice?
(1) Yes (X)
(2) ()
(3) Neutral ()
(4) ()
(5) No ()

17. Will this set of recommendations assist you in the care of your patients in your practice?
(1) Very often $(\mathrm{X})$
(2) ()
(3) Neutral ()
(4) Once ()
(5) Never ()

18. Please provide any additional comments you may have that were not addressed above.

Comment: Need to complete the sentence on bone modifying agents. Consider reconciling the comments related to the use of bevacizumab and sunitinib in "select" and "highly selected" patient populations with the language used in the Bottom Line, which states that neither of these agents should be offered. 
Table A1. ASCO/CCO CRPC Expert Panel

\begin{tabular}{|c|c|}
\hline Member & Affiliation \\
\hline Ethan Basch, MD*† & University of North Carolina, Chapel Hill, NC \\
\hline Andrew Loblaw, MD† & Odette Cancer Centre, Sunnybrook Health Sciences Centre, Toronto, Ontario, Canada \\
\hline Charles Bennett, MD & University of South Carolina, Columbia, SC \\
\hline Michael Carducci, MD & Johns Hopkins University, Baltimore, MD \\
\hline Ronald C. Chen, MD & University of North Carolina, Chapel Hill, NC \\
\hline James N. Frame, MD & Charleston Area Medical Center Health Systems, Charleston, WV \\
\hline Sebastian Hotte, MD & McMaster University, Hamilton, Ontario, Canada \\
\hline Kristina Garrels, MD & Private practice, Fargo, ND \\
\hline Michael W. Kattan, MBA, PhD & Cleveland Clinic, Cleveland, $\mathrm{OH}$ \\
\hline Derek Raghavan, MD & Carolinas Health Care/Levine Cancer Institute, Charlotte, NC \\
\hline Mary-Ellen Taplin, MD & Dana-Farber Cancer Institute, Boston, MA \\
\hline Fred Saad, MD & University of Montreal, Montreal, Quebec, Canada \\
\hline Katherine S. Virgo, PhD & Emory University, Atlanta, GA \\
\hline James Williams, MS, SPHR & Pennsylvania Prostate Cancer Coalition, Camp Hill, PA \\
\hline Eric Winquist, MD & London Health Sciences Centre, London, Ontario, Canada \\
\hline Ted Wootton & Patient representative, Toronto, Ontario, Canada \\
\hline
\end{tabular}

NOTE. ASCO staff: Thomas K Oliver and R. Bryan Rumble. CCO staff: Cindy Walker-Dilks.

Abbreviations: ASCO, American Society of Clinical Oncology; CCO, Cancer Care Ontario; CRPC, castration-resistant prostate cancer.

*Panel chair.

+Writing group member. 